\title{
Elagolix Sodium: Novel GnRH Antagonist for the Treatment of Endometriosis
}

\author{
Joyson Paul, Rohit Bhatia* \\ Department of Pharmaceutical Analysis, ISF College of Pharmacy Moga, Punjab, India-142001
}

Correspondence to: Rohit Bhatia, Department of Pharmaceutical Analysis, ISF College of Pharmacy Moga, Punjab, India-142001; Email: Bhatiarohit5678@gmail.com Received date: May 2, 2021; Accepted date: May 15, 2021; Published date: May 22, 2021

Citation: Paul J, Bhatia R (2021) Elagolix Sodium: Novel GnRH Antagonist for the Treatment of Endometriosis. J Clin Anesthes Res 2(1): pp. 1-6. doi:10.52916/jcar214007 Copyright: @2021 Paul J, et al. This is an open-access article distributed under the terms of the Creative Commons Attribution License, which permits unrestricted use, distribution and reproduction in any medium, provided the original author and source are credited.

\section{ABSTRACT}

Endometriosis is a category of lesions and fibroids which occur in the innermost lining of the uterus that is the endometrial layer and spreads to the other parts of the neighboring tissues. It is characterized by inflammation, pelvic pain, menstrual bleeding, and Dysmenorrhea. Endometriosis exists in 3 forms based on its spreadability. i.) superficial peritoneal lesions ii.) deep infiltrating lesion and iii.) cyst. Traditional treatments involve are NSAIDS, Oral contraceptives, Aromatase inhibitors, and $\mathrm{GnRH}$ agonists. Elagolix emerges out to be the latest potent drug that acts by inhibiting the $\mathrm{GnRH}$ receptor. Unlike other allopathy medicine, it is not an asymptomatic pain reliever but acts on the root cause of the disease. FDA has approved it for specific treatment of endometriosis in July 2018. It is believed that endometriosis occurs by an increase in the production of estrogen. Elagolix competitively binds to the $\mathrm{GnRH}$ receptors and prevents the binding of the Gonadotropin hormone flowing through blood capillaries from the Hypothalamus to the pituitary gland and thereby stops the formation of Oestrogen in the reproductive system which ultimately ceases in the proliferation of endometrial layers and tissue spread. In estrogen biosynthesis, the aromatase P450 enzyme plays a vital role. Elagolix belongs to BCS class III and available in the oral dosage form of $150,200 \mathrm{mg}$. It is rapidly absorbed and Cmax reaches within 1 hour. The plasma protein binding is $80 \%$. In this review, various aspects related to Elagolix sodium have been summarised, which include pathophysiology, Mode of Action, Structure-activity relationship, Pharmacokinetics, pharmacodynamics, and clinical studies with minimal side effects.

\section{Keywords:}

Endometriosis, GnRH antagonist, Elagolix sodium, Aromatase P450, Estrogen, Fibroids.

\section{Introduction}

Endometriosis is a disease that occurs in the innermost lining of the Uterus, where the proliferation of cells leads to the formation of fibroids. Endometriosis is a non-cancerous uterine Leiomyoma which is the outgrown tissues in the endometrium layer [1].It is defined by a benign inflammatory disease characterized by ectopic endometrial glands and stroma [2]. Endometriosis occurs with no specific symptoms and affects around $5-10 \%$ of women in their active menstrual cycle $[3,4]$. Approximately 175 million females worldwide are suffering from this deadly disease which is estimated to be 1 in 10 women is affected by endometriosis between the age of 15 to 49 [5]. Brown et al. says that more than 1.8 billion women receive the diagnosis of endometriosis. Endometriosis spread from superficial peritoneal lesion to cysts in the ovaries, myometrium and even it spreads to the rectum. Based on its severity of spreading the disease endometriosis is classified into 3 subtypes: (i)superficial peritoneal lesions, (ii)deep infiltrating lesions, and (iii)cysts. The superficial peritoneal lesions are thin film that coats the inner surface of the pelvic cavity [6].
The $90 \%$ chances are during menstruation the pieces of endometrium reflux in the abdominal cavity through fallopian tubes adhere to the peritoneal lining and develop into lesions [7]. In rare cases the superficial peritoneal transformation may turn into malignancy [8]. Deep infiltrating lesions are the second form of endometriosis where small fibroids of $5 \mathrm{~mm}$ size were found penetrating the peritoneal surface it is characterized by stroma and ectopic endometrial glands and the disease known as Adenomyosis. It spreads to the posterior area, the cervical part to the posterior wall of the vagina, and the wall of the rectum [6]. Cyst is a third form of endometriosis because it originates from the inner lining of the uterus and spreads to the ceiling of the ovarian fossa therefore is called an ovarian endometrioma. The chances of spreading in ovaries are $17-44 \%$. It is often associated with pelvic pain and heavy bleeding. The heavy bleeding and severe pelvic pain are due to $\mathrm{GnRH}$, inflammation, and dyspareunia. The susceptibility of endometriosis is 5 times more in those women having dyspareunia.

Also, Women diagnosed with endometriosis has $80 \%$ chances of dysmenorrhea and $40 \%$ chances of infertility [9]. The possible cause of endometriosis is the overexpression of the enzyme aromatase cytochrome $\mathrm{P} 450$ which is responsible for the growth of estrogen and converts androgens into estrogen which plays a vital role in the formation of the endometrium layer. Aromatase 
P450 is regulated by the tissue-specific promoters present in the placenta (promoter I.1), adipose tissue (promoters I.4, I.3), and gonads (promoter II). The population of the Aromatase arises in the use of each promoter [10]. Through mRNA transcription the majority of P450arom are transcripts into the cells contained gonadal type promoter II and very few in other cells. Because of the inflammatory nature of endometriosis [11], it was found that Prostaglandin receptors stimulate the P450arom to promote estrogen production [12]. PGE2 is responsible for the increment in endometrium stromal cells by 19 to 44 times in the production of P450arom. Therefore, PGE2 is potentially the primary stimulator of P450arom. As PGE2 stimulates the stromal cells of endometriosis, the promoter II of gonads over-regulates the CAMP pathway and increases the intracellular concentration level which leads to the production of estrogen and ultimately leads to inflammation, lesion and fibroids in the later stage.

\section{Pathogenesis}

The exact pathogenesis of endometriosis is still unclear and many researchers gave their theories but out of them only four theories are popular and explain the pathogenesis to some extent [13].

4 popular theories believe to explain the pathogenesis of endometriosis:

- Retrograde menstruation

- Vascular and lymphatic dissemination

- Impaired immunity

- Hereditary and stem cells

\section{Retrograde menstruation}

Retrograde menstruation is also called Sampson's theory which states that during menstruation the remains of endometrial tissue back trap into the fallopian tube and reach to the ovaries which causes inflammation and outgrown tissues. The tissue back trap is called the retrograde flow. And therefore, repeated retrograde flow led to the formation of the fibroids. Sampson's theory failed to explain that why endometriosis occurs in only $10 \%$ of women when retrograde menstruation is found in $80 \%$ of women.

\section{Vascular and lymphatic dissemination}

This theory says many lymphatic blood vessels provide blood supply into the uterine endometrial layer and other parts of the reproductive system. It is believed that some of the tissues of the endometrial layer go into the blood vessels and travels to the fallopian tube, ovaries, and pelvic region and this repeated process promote the formation of endometriosis.

\section{Impaired immunity}

Endometrial tissue starts to pour out of the uterine tube into the pelvic region as it deposits the endometrial tissue. The white blood cells reach the pelvic region. They bind with the haptoglobin proteins found in the patients of endometriosis and increase the Interleukin production. Other cytokines that migrate to the peritoneal fluid include macrophage migration inhibitory factor, TNF-alpha, IL-1beta, IL-6, IL-8. The growth factors of PGE2 cause adhesion, proliferation, and inflammation. The white blood cells destroy the endometrial layer instead of outgrown endometrial tissues present in the peritoneal layer, fallopian tube, and ovaries. Because WBCs are unable to detect

\section{Hereditary}

A theory says if a mother had endometriosis it is likely to have the same disease in her daughter as well. But the problem with that is there is plenty of cases that prove this theory $100 \%$ correct.

\section{Stem cells}

Inside of endometrium, there are a bunch of stem cells that are undifferentiated and can regrow after a while. They renew to form the endometrium layer. These stem cells reach the fallopian by retrograde menstruation and due to the ability to renew they grow and form fibroids and ultimately cause endometrioses.

\section{Pathophysiology}

Due to inflammation in the neighbouring tissues by various pathogenesis theories, the excess production of Prostaglandin triggers the Aromatase enzyme P450 to increase the reaction rate and formation of estrone from androstenedione which is a first estrogen. The pathophysiology of endometriosis has been outlined in figure 1.

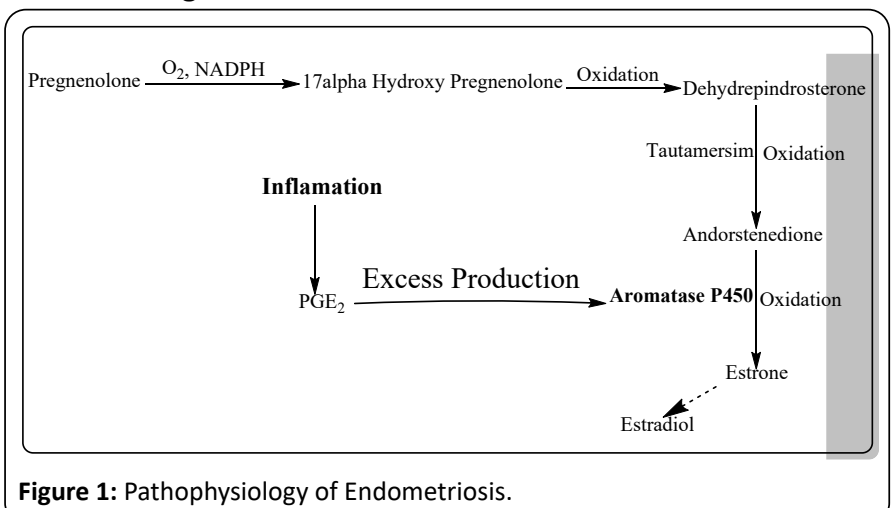

\section{Treatment}

The first-line treatment of endometriosis is some drugs that work on the symptoms of endometriosis. For the first-line treatment, we use NSAIDS for pelvic pain relief and dysmenorrhoea. Most commonly used among NSAIDs are ibuprofen, aspirin, and naproxen [15]. However one study revealed a low positive effect of NSAIDs on pain relief in women suffering from endometriosis [5]. The other first-line drugs are combined oral contraceptives. Second- and third-line drugs for treatment are progestins, an aromatase inhibitor, and a GnRH agonist. GnRH agonists are not recommended to adolescents because of their effect on bone. Aromatase inhibitor shows good results by decreasing the production of estrogen and cessation of the menstrual cycle during endometriosis in women [16]. Studies showed that prolong use of aromatase inhibitors cause decrease in bone mineral density.

\section{GnRH antagonist}

Elagolix is a $\mathrm{GnRH}$ antagonist and works opposite to $\mathrm{GnRH}$ agonist in which downregulation leads to desensitization of the receptor and the therefore the release of estrogen decreases and ceases in the formation of the endometrium layer. Elagolix belongs to a class of fluorinated carbons [17]. Elagolix is in the early stages of treating heavy menstrual bleeding and uterine leiomyoma. The drug is known by its brand name ORILISSA and is manufactured by the neucrine and Abbvie Inc. 


\section{Chemistry}

The structure and synthesis of elagolix have been depicted in figure 2 and 3.<smiles>COc1cccc(-c2c(C)n(Cc3c(F)cccc3C(F)(F)F)c(=O)n(C[C@H](NCCCC(=O)O)c3ccccc3)c2=O)c1F</smiles>

4-[[(1R)-2-[5-(2-fluoro-3-methoxyphenyl)-3-[[2-fluoro-6-(trifluoromethyl)phenyl]methyl]-4-methyl-2,6-dioxopyrimidin-1-yl]-1phenylethyl]amino]butanoic acid

Figure 2: Structure of elagolix.<smiles>CCn1c(C)cc(=O)[nH]c1=O</smiles><smiles>Cc1c(Br)c(=O)[nH]c(=O)n1Cc1c(F)cccc1C(F)(F)F</smiles><smiles>CC(C)(C)NCc1ccccc1</smiles><smiles>COc1cccc(-c2c(F)n(Cc3cc(F)ccc3F)c(=O)n(C[C@H](NCCCC(=O)[O-])c3ccccc3)c2=O)c1F</smiles><smiles>COc1cccc(-c2c(C)n(Cc3cc(C(F)(F)F)ccc3F)c(=O)n(C[C@H](C)c3ccccc3)c2=O)c1F</smiles><smiles>COc1cccc(B(O)O)c1F</smiles><smiles>CN(C)Cc1c(F)cccc1C(F)(F)F</smiles>

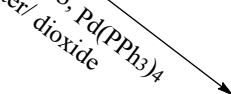<smiles>CCCN[C@@H](Cn1c(=O)c(-c2cccc(OC)c2F)c(C)n(Cc2cc(F)ccc2F)c1=O)c1ccccc1</smiles>

Figure 3: Synthesis of elagolix sodium. 


\section{Mode of action}

The Hypothalamus present in the forebrain and pituitary gland below it receives a signal from the peripheral nervous system and funnels the signal into pituitary glands which control the other endocrine glands and our body responds to the environment. $\mathrm{GnRH}$ hormone releases in the hypothalamus and signals the anterior pituitary gland to release FSH and LH (Gonadotropins) through blood circulation this gonadotropin reaches the female reproductive system. Where $\mathrm{LH}$ triggers the theca cells and through biosynthesis produces estrone and oestradiol which are the first estrogens [18]. Estrogens produce the endometrial layer to support the egg in the uterus. Elagolix competitively acts on the anterior pituitary receptor gland in place of $\mathrm{GnRH}$ and stops all the above processes of formation of the Gonadotropins and Oestrogens. In this way, the production of estrogen reduces and the formation of the endometrial layer decreases in and outside the formation of the endometrial layer decreases in and outside the uterus. When the release of estrogen release is suppressed the condition is known as the hypoestrogenic condition. The mode of action of elagolix has been outlined in Figure 4 .
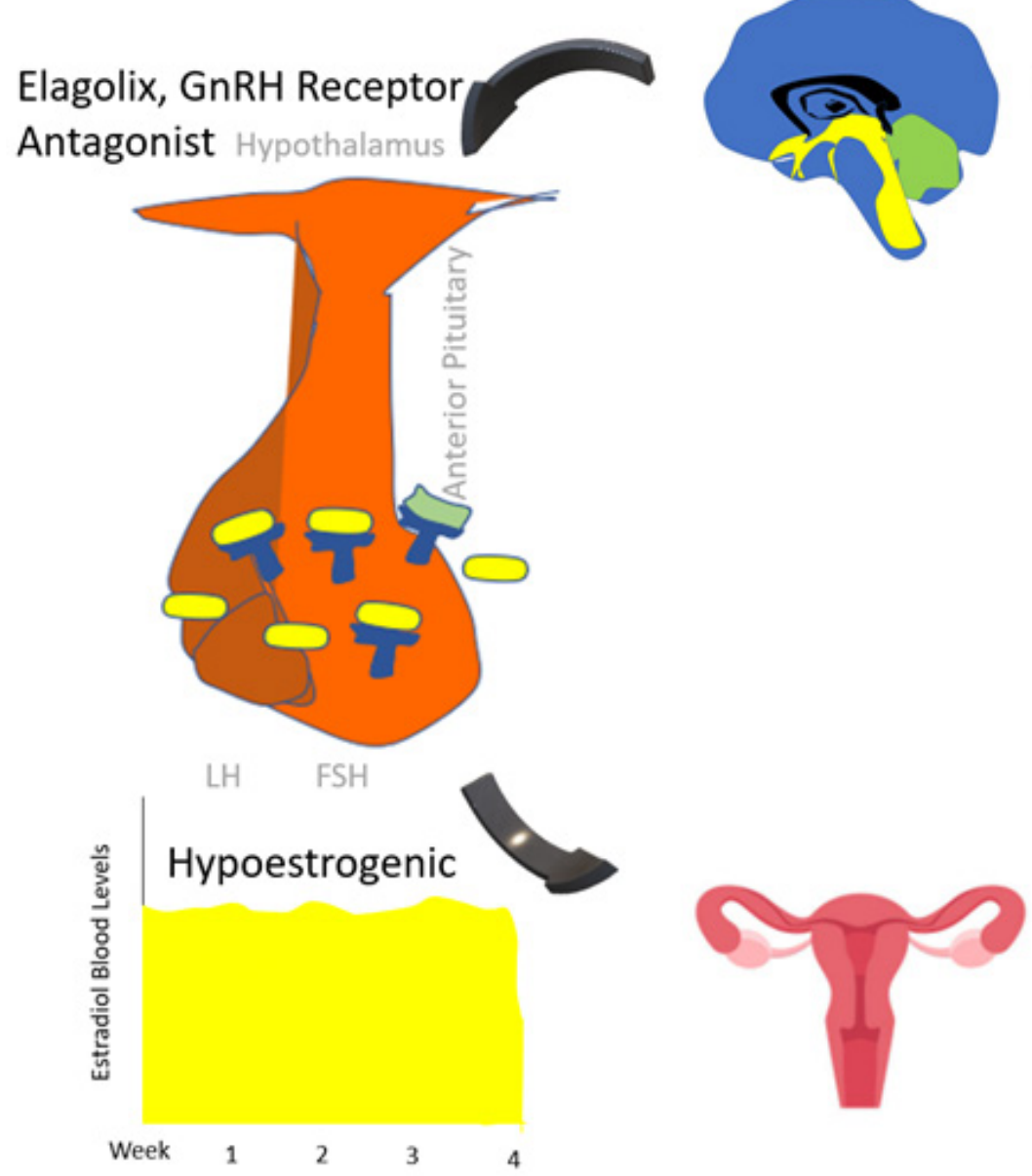

GnRH Receptor
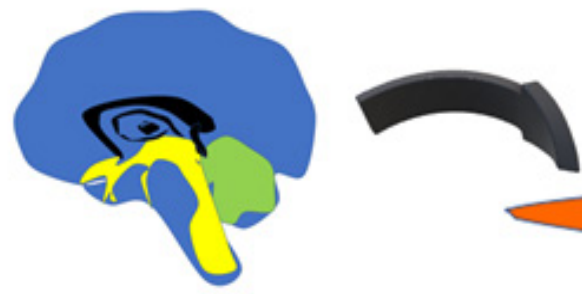

Endogenous $\mathrm{GnRH}$

Receptor Function
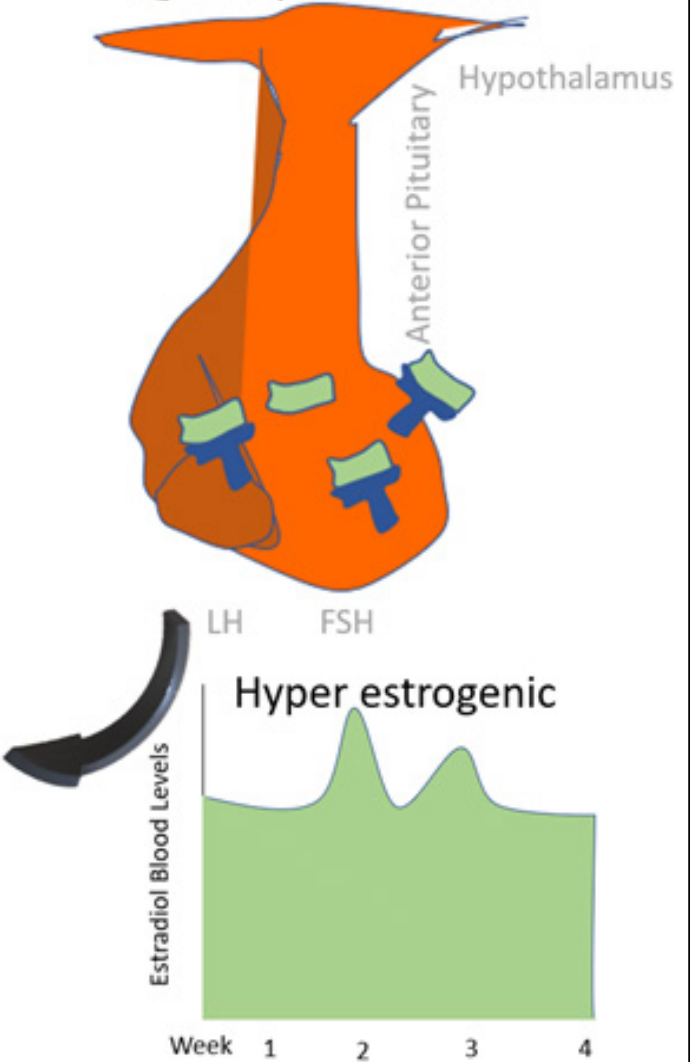

Elagolix Sodium, competitive antagonist

Figure 4: Mode of action of elagolix.

\section{Structural Activity Relationship}

The benzyl group at position 1 (arm1) of the uracil core is essential. Position 3 of uracil core is termed arm 2 along with butyrate moiety (Figure 5). Phenyl group forms pie-pie interactions with $\mathrm{N}$ - terminus. Incorporation of butyrate moiety might increase the solvent excess and water mediated interaction. Arm 3 at position 5 of uracil core makes hydrophobic interactions with side chain of residues in $\mathrm{N}$ terminus of receptor. Methyl group at position 6 of Elagolix contribute to high affinity ligand binding [19].

\section{Clinical trials (Application No: NCT01931670)}

The Phase 1 trials were initiated in February 2004. The phase 2 trials were initiated in April 2005. Uterine leiomyoma associated endometriosis Phase 2 studies were initiated in September 2013. Between 2012 to 2016 various studies were performed ELARIS EM-IV, II, III and I.(clinical trials.org) [20]. In 2016 a global study was performed to evaluate the safety and efficacy of elagolix in subjects with moderate to severe endometriosisassociated pain (ELARIS EM-II). The study consists of 815 participants having composite pelvic signs and symptoms score 


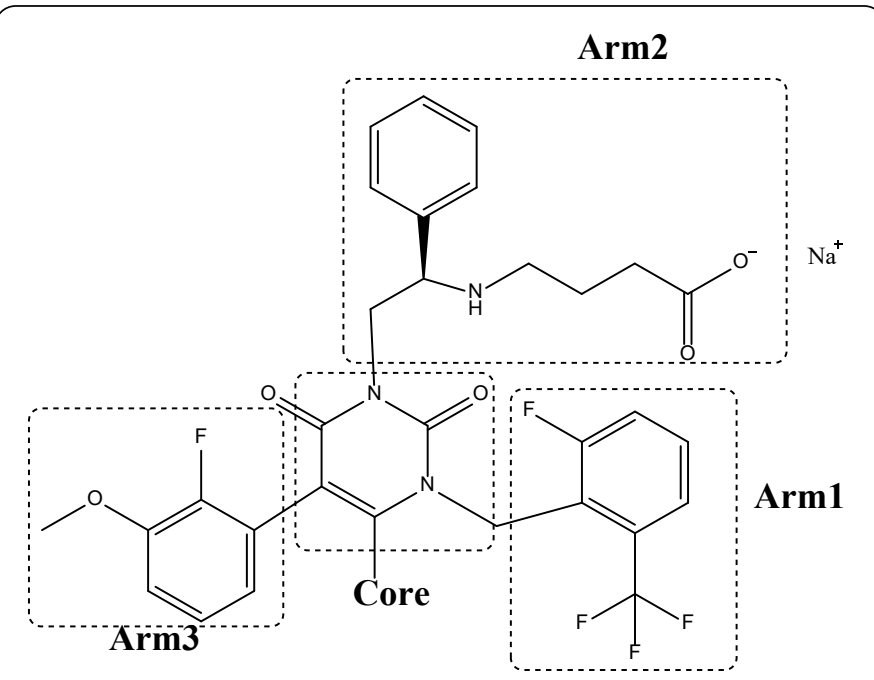

Figure 5: Structural features of elagolix with respect to activity.

of 6 or greater and dysmenorrhoea. The protocol of the clinical trial consists of 4 parts. 1) washout period, 2) screening period of up to 100 days before the first dose, 3) 6 months, and 4) a post-treatment follow-up period of up to 12 months and electronic diary to record responses. The subject using elagolix of doses $150 \mathrm{mg}$ and $200 \mathrm{mg}$ for 6 months. It was found that there was a reduction of -0.85 or greater in the daily assessment of Dysmenorrhea (DYS) pain scale as well decreased in analgesic use for endometriosis-associated pain. And in the Non-menstrual pelvic pain scale, a reduction in -0.43 or greater was recorded as well as no increased use of analgesics for endometriosis-associated pain [21]. At the end of 2016, the preregistration for endometriosis in the USA and priority review status was granted in the USA in October 2016. The prescription drug user fee act (PDUFA) was extended to the third quarter of April 2018. In July 2018 the Elagolix sodium was registered for treatment for endometriosis in the USA. Still, Phase 3 clinical trials are going on and will last in 2022.

\section{Pharmacodynamics}

Elagolix is a highly potent non-peptide $\mathrm{GnRH}$ antagonist that competitively binds to $\mathrm{GnRH}$ receptors in the pituitary gland by blocking the endogenic $\mathrm{GnRH}$ signaling, elagolix dominates and decreases the Luteinizing Hormone (LH) and FollicleStimulating Hormone (FSH), resulting in diminishing estradiol and progesterone production. Elagolix when administered orally of doses $150 \mathrm{mg}$ twice daily in a clinical trial in the healthy subject it suppresses the LH, FSH, estradiol, and progesterone in a dose-dependent manner [22]. Women that participate in phase III trials having endometriosis dosed with $150 \mathrm{mg}$ once daily and $200 \mathrm{mg}$ twice daily.

\section{Pharmacokinetics}

Elagolix is dose-proportional in healthy premenopausal women (dose range 100-400 $\mathrm{mg}$ twice daily). It is rapidly absorbed with Cmax reached within 1 hour of the oral dose. Plasma protein binding is $80 \%$. Cmax reduces by 24 and $36 \%$ when elagolix is administered orally with a high-fat content meal as compared to fasting. It belongs to BCS class III [23].

\section{Adverse effects}

Elagolix sodium is the latest drug in the treatment of endometriosis. Nausea, headache, and nasopharyngitis are some common side effects [24]. It overcomes the major side effects that occur by using drugs to treat this disease is Bone Mineral Density (BMD)[25].

\section{Conclusion}

Endometriosis is a non-cancerous uterine leiomyoma characterised by outgrown tissues in the endometrium layer that arises in the innermost lining of the uterus, where cell proliferation results in the development of fibroids. We offered a thorough description of pathogenesis and pathophysiology in this study, with an emphasis on the experimental treatment of endometriosis with Elagolix Sodium, a recently approved $\mathrm{GnRH}$ antagonist. We included the synthesis, SAR, mode of action, pharmacodynamics, pharmacokinetics, and clinical trials that were conducted. The drug's potential applications include treating mild to serious uterine fibroids, as well as prostate cancer and other significant forms of cancer.

\section{References}

1. Hickey M, Ballard K, Farquhar C. Endometriosis. BMJ. 2014;348(mar19 5):g1752.

2. Zondervan KT, Becker CM, Koga K, et al. (2018) Endometriosis. Nat Rev Dis Prim 4(1): pp. 9.

3. Fourquet J, Gao X, Zavala D, et al. (2010) Patients' report on how endometriosis affects health, work, and daily life. Fertil Steril 93(7): pp. 2424-2428.

4. endometriosis.org. Facts about endometriosis "Endometriosis.org. Published 2017. Accessed January 19, 2021. http://endometriosis.org/resources/articles/facts-aboutendometriosis/

5. Brown J, Tj C, Allen C,et al. (2017) Nonsteroidal antiinflammatory drugs for pain in women with endometriosis (Cochrane Database Syst Rev 1(1): pp. CD004753.

6. Gałczyński K, Jóźwik M, Lewkowicz D, et al. (2019) Ovarian endometrioma - A possible finding in adolescent girls and young women: A mini-review. J Ovarian Res 12(1): pp. 104.

7. Marchand E, Hequet D, Thoury A, et al. (2013) Malignant transformation of superficial peritoneal endometriosis lesion. BMJ Case Rep. 2013: pp. 7730.

8. Kor E, Mostafavi SRS, Mazhin ZA, et al. (2020) Relationship between the severity of endometriosis symptoms (dyspareunia, dysmenorrhea and chronic pelvic pain) and the spread of the disease on ultrasound. BMC Res Notes 13(1): pp. 1-8.

9. Mori T, Ito F, Koshiba A, et al. (2018) Aromatase as a target for treating endometriosis. J Obstet Gynaecol Res 44(9): pp. 16731681.

10. Noble LS, Takayama K, Zeitoun KM, et al. (1997) Prostaglandin E 2 Stimulates Aromatase Expression in Endometriosis-Derived Stromal Cells. J Clin Endocrinol Metab 82(2): pp. 600-606.

11. Bulun SE, Yang S, Fang Z, et al. (2001) Role of aromatase in endometrial disease. J Steroid Biochem Mol Biol 79(1-5): pp. 19-25.

12. Bulun SE, Gurates B, Fang Z, et al. (2002) Mechanisms of 
excessive estrogen formation in endometriosis. J Reprod Immunol 55(1-2): pp. 21-33.

13. Burney RO, Giudice LC (2012) Pathogenesis and pathophysiology of endometriosis. Fertil Steril 98(3): pp. 511519.

14. Taylor HS, Dun EC, Chwalisz K (2019) Clinical evaluation of the oral gonadotropin-releasing hormone-antagonist elagolix for the management of endometriosis-associated pain. Pain Manag 9(5): pp. 497-515.

15. Giudice LC (2005) Endometriosis in Clinical Practice. N Engl J Med 362(25): pp. 2389-2398.

16. Słopień R, Męczekalski B (2016) Aromatase inhibitors in the treatment of endometriosis. Prz Menopauzalny 15(1): pp. 4347.

17. Lamb YN (2018) Elagolix: First Global Approval. Drugs 78(14): pp. 1501-1508.

18. Shebley M, Polepally AR, Nader A, et al. (2020) Clinical Pharmacology of Elagolix: An Oral Gonadotropin-Releasing Hormone Receptor Antagonist for Endometriosis. Clin Pharmacokinet 59(3): pp. 297-309.

19. Yan W, Cheng L, Wang W, et al. (2020) Structure of the human gonadotropin-releasing hormone receptor $\mathrm{GnRH} 1 \mathrm{R}$ reveals an unusual ligand binding mode. Nat Commun 11(1): pp. 1-10.
20. A Clinical Study to Evaluate the Safety and Efficacy of Elagolix in Subjects With Moderate to Severe Endometriosis-Associated Pain - Full Text View - ClinicalTrials.gov. Accessed January 28, 2021. https://www.clinicaltrials.gov/ct2/show/NCT01620528

21. NCT01931670. A Global Phase 3 Study to Evaluate the Safety and Efficacy of Elagolix in Subjects With Moderate to Severe Endometriosis-Associated Pain. Https://clinicaltrials.gov/show/ nct01931670.

22. Struthers RS, Nicholls AJ, Grundy J, et al. (2009) Suppression of gonadotropins and estradiol in premenopausal women by oral administration of the nonpeptide gonadotropin-releasing hormone antagonist elagolix. J Clin Endocrinol Metab 94(2): pp. 545-551.

23. Winzenborg I, Nader A, Polepally AR, et al. (2018) Population Pharmacokinetics of Elagolix in Healthy Women and Women with Endometriosis. Clin Pharmacokinet 57(10): pp. 1295-1306.

24. Surrey ES, Soliman AM, Agarwal SK, et al. (2019) Impact of elagolix treatment on fatigue experienced by women with moderate to severe pain associated with endometriosis. Fertil Steril 112(2): pp. 298-304.

25. Archer DF, Soliman AM, Agarwal SK, et al. (2020) Elagolix in the treatment of endometriosis: impact beyond pain symptoms. Ther Adv Reprod Heal 14. 